\title{
Periodontal Dressing
}

\author{
Dr. Triveni Kale, Dr.Nitin Dani, Dr.Tejas Patange \\ Reader \& Guide Dept. Of Periodontology MGV'S KBH Dental College \& Hospital, Nashik. \\ Maharashtra,India \\ HOD\& GUIDE Dept. Of PeriodontologyPost graduate student
}

Keywords : periodontal dressing, pack, pac,surgical dressing

\section{Introduction:}

Periodontal dressing is a surgical dressing used post operatively to cover and protect the surface of surgical wound created by periodontal therapy.The sequelae of periodontal surgery are commonly pain, swelling, inflammation and bleeding and thus, many periodontists advocate that some form of protection should be applied over the injurious tissue so that the affected area is shielded from further insult ${ }^{1}$.

Prior to introduction of the first periodontal pack by Dr. AW Ward in $1923^{3}$, surgical eradication of periodontal disease was accompanied by the undesirable sequelae like pain, hemorrhage, unsatisfactory control of granulation tissue and sloughing._fig 1

Thus, $\mathrm{s}$ it can be concluded that wound protection, patient's comfort and some degree of hemostasis and tissue stasis are considered to be desirable effects in dressings.

\section{Ideal requisites of periodontal dressings 9}

- soft, but still have enough plasticity and flexibility to facilitate its placement in the operated area and to allow proper adaptation.

- set within a reasonable time.

- sufficient rigidity to prevent fracture and dislocation.

- smooth surface after setting to prevent irritation to the cheeks and lips.

- bactericidal properties to prevent excessive plaque formation.

- Not interfere with healing.

- dimensional stability to prevent salivary leakage.

- not induce possible systemic detrimental effects and allergic reactions.

- acceptable taste.

- economical and easily available.

- good shelf life.

\section{Rationale For Usage Of Periodontal Dressings ${ }^{2}$}

- Protection of the wound area:

- Enhancement of patient comfort:

- Maintenance of a debris free area:

- Control of bleeding: from trauma.

- Periodontal dressings also protect newly exposed root surfaces from temperature changes and protect sutures.

- Protects surgical healing areas from irritants such as hot or spicy foods.

\section{Classified On The Basis Of Presence Or Absence Of Eugenol.}

Zinc oxide Eugenol Dressing (Hard pack)

Non-Eugenol Dressing (Soft pack)

Other types are as follows;

Collagen materials.

Methacrylate gels.

Light cure dressing.

Cyanoacrylate.

Oral adhesive bandage

Wax pack. 


\section{1) Zinc oxide Eugenol Dressing}

Zinc oxide eugenol dressings are available in Powder \& liquid form e.g Wards wondr pak, Kirkland -Kaiser pak, Box pak or in Paste form e.g Peridress, PPC etc.

Powder and liquid form: These forms of dressings containing eugenol are prepared by mixing a powder and a liquid. The powder is composed of zinc oxide, tannic acid, rosin, kaolin, zincstearate, asbestos.

Functions : Zinc oxide is an antiseptic and astringent,

tannic acid is hemostatic but has been associated with liver disease,

rosin acts as a filler, increases the strength, speeds the reaction and it yields a smoother and more homogenous product.

The liquid contains eugenol, peanut oil, rosin.

Eugenol is an anesthetic, antiseptic and obtundent.

Peanut oil regulates the setting time.

When the components of the zinc oxide eugenol dressing are mixed, setting (hardening) occurs as a result of chemical interaction between zinc oxide and eugenol forming zinc eugenolate.

B. Paste form: These forms of dressing containing eugenol are dispensed as two separate pastes.

Tube-1 base $-87 \%$ zinc oxide,

$13 \%$ fixed vegetable or mineral oil,

Tube- 2 accelerator $-12 \%$ oil of clove or eugenol,

$50 \%$ gum or polymerized rosin,

$20 \%$ filler (silica type),

$3 \%$ lanolin,

Disadvantages of Zinc oxide eugenol dressings :

Unpleasantness

Spicy taste

Burning sensation

Sets to hard cement like consistency.

lack of smoothness (gives rise to rough edges and ulceration) therefore difficulty in adaptation

Frequency of fractures

\subsection{B.) Non-Eugenol Dressings}

The various zinc oxide non-eugenol dressings available are

Coe-pak,

Peripac,

Vocopac,

Perio care,

Collagen dressings,

Barricaid, Cyanoacrylates and

Tissue conditioners.

Coepak: The most common and widely used non-eugenol dressing is Coepak (Coe Laboratories Inc., Chicago, IL), which is supplied as two tube or as an automixing system contained within a syringe

Base Tube: contains rosin, cellulose, natural gums (for cohesiveness) and waxes, fatty acids, chlorothymol (bacteriostatic agent), zinc acetate, alcohol.

Accelerator Tube: contains zinc oxide, vegetable oil (for plasticity), chlorothymol, magnesium oxide, silica, synthetic resin, coumarin lorothidol (a fungicide) (Fig.2).

Zinc oxide is an antiseptic and astringent, magnesium oxide helps in setting reaction, rosin regulates the setting time, chlorothymol is a bacteriostatic agent. When the two pastes are mixed together, it sets by chemical reaction, between an ion and fatty acid. Setting is firm but softer than that of zinc oxide eugenol dressings.

The Automixing system

\section{3) COLLAGEN DRESSING}

It is collagen sponge; an example of this dressing is CollaCote (Helitrex, lac). This material is Type-1 collagen, which is derived from bovine Achilles tendon. It is a completely resorbable dressing that is used to cover and protect palatal graft sites,. fig 4 .

\section{4) METHACRYLIC GELS}

Methacrylic gels were used primarily in dentistry as tissue conditioners or as denture liners. 


\section{5) LIGHT CURE DRESSINGS.}

It is available in a syringe for the direct application, or dispensing on a mixing pad and placement intra orally. Most acceptable light cured periodontal dressing used now a day is Barricaid (fig 5). It is tinted for superior esthetics, offers protection and appealing appearance and usually used in anterior region. The principle ingredients of these materials are polyether urethane dimethacrylate resin, silanated silica, visible light cure (VLC) photoinitiater and accelerator, stabilizer, colorant. It contains polymerisable monomers that may cause skin sensitization (allergic contact dermatitis) in susceptible persons

fig 5. Barricade is designed for both direct and indirect placement ${ }^{(3)}$. Direct placement ${ }^{3}$ :

Using a sterile, dry $2 \times 2$ gauze, dry the buccal or lingual tooth surfaces adjacent to the surgical site. Remove the tip from the disposable syringe. Dispense the material at the juncture of the cervical one-third of the teeth

Indirect placement ${ }^{3}$ :

Place a thin layer of lubricant on a clean mixing pad.With gloved finger, lightly lubricated, roll the ribbon of dressing off the pad. The material may be muscle molded, contoured with a plastic instrument, carver, or finger pressure. Expose barricaid to a visible light-curing unit for at least 10 seconds per tooth per side (buccal or lingual).

\section{6.) CYNOACRYLATE}

In 1966, tissue adhesives were introduced to dentistry. Dr. S.N. Bhaskar conceived the idea of their potential in periodontics. Bhaskar et al (1966) ${ }^{12}$ reported on the use of cyanoacrylates as a dressing over experimentally produced tongue injuries in rats and stated that butyl and propyl forms were phagocytosed locally and that healed areas following the use of these adhesives were indistinguishable from those where silk sutures were used.

The basic formula of cyanoacrylates is $\mathrm{CH}=\mathrm{C}(\mathrm{CN})$-COOR.. Cyanoacrylate is either applied in drops or sprayed on the tissue. The advantage is that they function without the use of special catalysts. ${ }^{13}$

\subsection{INTRA-ORAL ADHESIVE BANDAGES:}

.. It is composed of polyisobutylene, sodium carboxy methyl cellulose, pectin, gelatin and a polyethylene backing and is supplied in this form $(2 \times 4 \times 0.02)$ and a thick form $(3 \times 4 \times 0.06)$.

\subsection{WAX PACK:}

Mixture of coca butter and paraffin in equal amounts, available in thin strips and can be cut into prescribed sizes and applied after gingivectomy and other surgical procedures.

\section{CHLORHEXIDINE AS AN ADDITIVE TO DRESSING:}

Asboe-Jorgensen et al $(1974)^{14}$ found that a dressing containing chlorhexidine promoted healing because it decreases the bacterial colonization of the wound.Following bilateral flap surgery, one side received a $0.2 \%$ chlorhexidine rinse interdentally, and healing was examined for up to 36 days post surgically. The sites treated with chlorhexidine had less gingival exudate, less bleeding and lower gingival index scores than the control sites.

5.1 Linear dimensional changes:

\section{Physical Properties:}

5.2 Viscosity:

5.3Reaction with restorations:

5.4 Adhesion:

5.5 RETENTION:

6.Alternative dressing procedures:

The technique for placing the dressing must be modified for edentulous areas and for isolated or widely separated teeth

7.Retention of Dressings:

These include wire ligation, suturing the dressing with cotton tape embedded in it, a variety of stents and splints, which fit over the teeth and gingiva, the use of interproximal spiral saws with cotton thread, and foil. Some techniques utilizing a copper band for retention on a solitary tooth surgical site has also been successfully used.

8. Removal of dressing and return visit ${ }^{20}$ :

When the patient return after 1 week, the periodontal dressing is taken off by inserting a surgical hoe along the margin and exerting gentle lateral pressure.

9.Re-packing ${ }^{20}$ :

A low pain threshold who are particularly uncomfortable when the pack is removed 
Unusually extensive periodontal involvement, or

Slow healing.

10.BIOLOGICAL SIDE EFFECTS

10.1 Tissue Irritation:

10.2.Effects on Cell Cultures:

10.3.Tissue Disturbance:

10.4.Allergy and sensitization

10.5.Asbestos-related Disease:

10.6.Bacterial Ecology:.

10.Whether or Not to Use a Dressing?

depends on the type of surgery (factors such as amount of surgical trauma or osseous surgery or flap adaptation) employed and personal preference of the dentist.

11.No Pack philosophy

Loe and Silness $(1961)^{27}$ noted that in the absence of a dressing complete healing still took place and concluded that a dressing has little influence on healing provided that the surgical area is kept clean.

.conclusion:

Clinical observations are mixed, but the consensus is that, from a healing point of view, it really does not matter whether a surgical site is dressed or not. After several weeks, dressed and undressed areas look similar.

\section{FIGURES}

Fig1. DR.A W Ward

Fig2.coe pack.

Fig3. Automix system

Fig 4.collagen dressing

Fig 5barricaid

Fig 6Zoe dressing

Fig 7 placing dressing
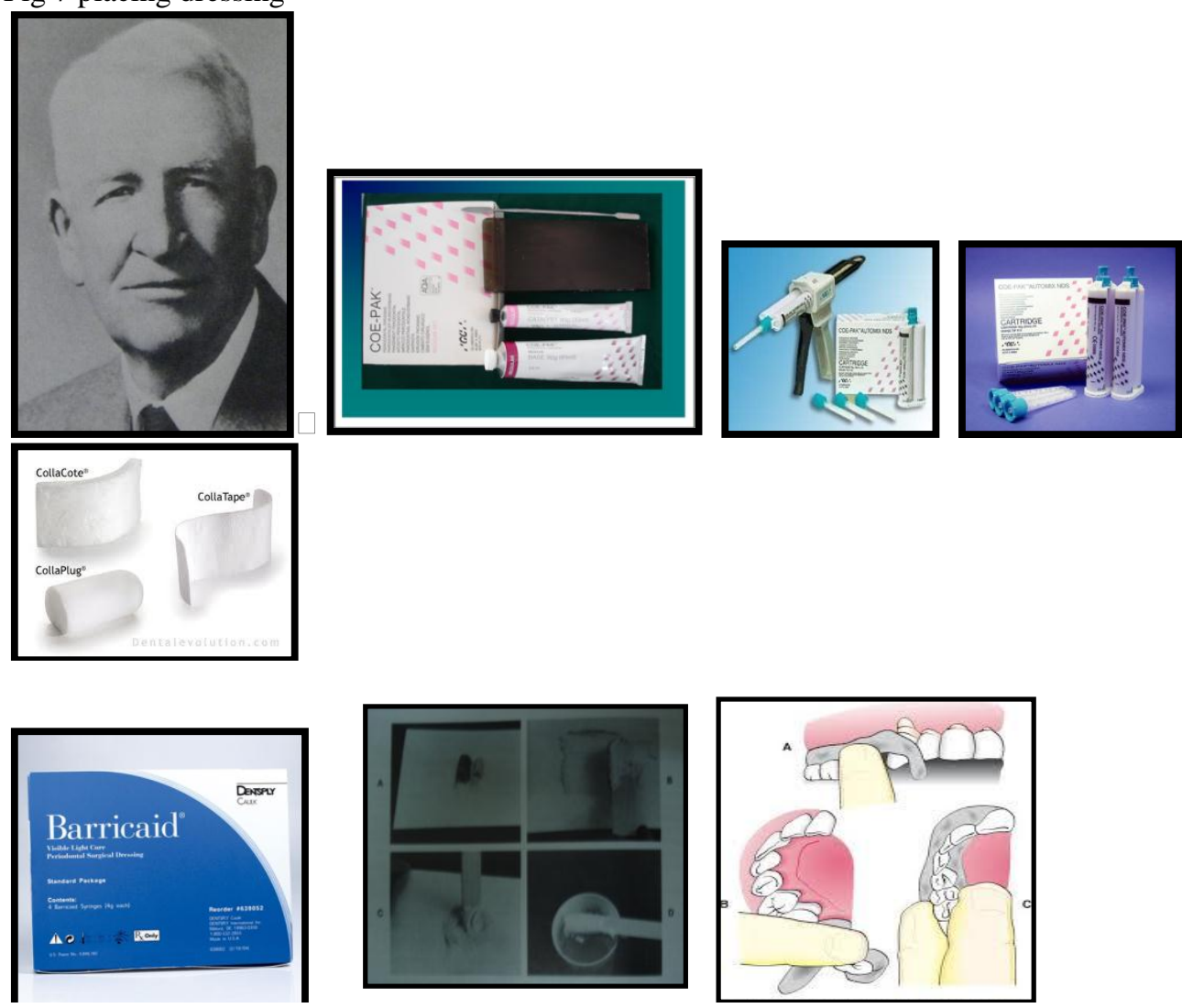


\section{References}

[1]. Linghorne W.J \& O'Connell D.C. The therapeutic properties of periodontal cement pack. Journal of the Canadian dental association (1949)

[2]. H. A. Sachs, A. Farnoush. Current Status of Periodontal Dressings. J. Periodontol. December, 1984; 55; 689-696

[3]. Muthukumarasamy, Nazargi Mahabob. Periodontal dressing: A Review. Jident issue 1 volume 1 october 2012; 24-33

[4]. Box H. K. and Ham A. W.: Necrotic gingivitis: its histopathology and treatment with an adherent dressing. Oral Health 37:721. 1942.

[5]. Orban, B.: The use of paraformaldehyde and oxygen in periodontal treatment. J Periodontology 14: 37.1943

[6]. Bernier, J. L., and Kaplan, H.: The repair of gingival tissue after surgical intervention. J Am Dent Assoc 35: 697, 1947.

[7]. Ariaudo AA, Tyrell HA. Repositioning and increasing the zone of attached gingival. J Periodontol. 1957;28(2):106-10

[8]. Weinreb. M. and Shapiro. S.: A clinical and histological investigation of the pressure pack method in periodontia. J Periodontal 35: $167,1994$.

[9]. K. David, Shetty Neetha. Periodonatl dressings: An informed view. J Pharm Biomed Sci. 2013, January; 26(26): 269-272

[10]. Thorstensen, R. Duguid. The effects of adding chlorhexidine and polyhexamethylene bisguanide to a light cured periodontal dressing material. Journal of oral rehabilitation 1996 23; 729-732

[11]. A. D. Gilbert, C. H. Lloyd. The Effect of a Light-Cured Periodontal Dressing Material on HeLa Cells and Fibroblasts InVitro. J Periodontol April 1994; 65; 324-329

[12]. Bhaskar, S. N.. Jacoway. J. R.. Margetis, P. M., et al.: Oral tissue response to chemical adhesives (cyanoacrylates). Oral Surg 22:294, 1966

[13]. J. O. Forrest. The use of cyanoacrylates in periodontal surgery. J. Periodontol. April, 1974; 45; $225-229$

[14]. Asboe-Jorgensen, V., Attstrom, R., Lang, N. P., and Löe, H.:Effect of chlorexidine dressing on the healing after periodontal surgery. J Periodontol 45: 13, 1974.

[15]. Pluss, E. M., Engelberger, P. R.. and Rateitschak, K. H.: Effect of Chlorhexidine on dental plaque formation under periodontal pack. J Clin Periodontol 2: 136, 1975

[16]. Gjerdet and E. Haugen. Dimensional changes of periodontal dressings. J dent res December 1977; 56; 1507-1511

[17]. T. Watts, e. C. Combe. Rheological aspects of non-eugenol periodontal dressing materials. Journal of oral rehabilitation, 1982, volume 9, pages 291-300

[18]. Haugen. E.. Espevik. S.. and Mjor. I. .: Adhesive properties of periodontal dressings—an in vitro study. J Periodont Res 1979 14: 487

[19]. Robinson R E. Osseous Coagulum for Bone Induction. J Periodont 1969, vol. 40, No.9: 503-510

[20]. Carranza: Clinical periodontology $; 10^{\text {th }}$ edition

[21]. Kreth. K.. Zimmermann. E. R., and Collings. C. K: Effect of periodontal dressings on tissue culture cells. J Periodontol 37 : 48. 1966.

[22]. (55)Hildebrand, C. N, and DeRenzis, F. .: Effect of periodontal dressings on fibroblasts in vitro. J Periodont Res 9: 114, 1974.

[23]. W. Binnie, J. Forrest. A study of tissue response to cyanoacrylate adhesive in periodontal surgery. J. Periodontol. August, 1974; 45; $619-625$

[24]. (59)(Ericksson. L.: Cyanoacrylate for closure of wounds in the oral mucosa in dogs. Odonlol Rery 27: 19.1976.

[25]. (63)Otterson EJ, Arra MC. Potential hazards of asbestos in periodontal packs. J Wis Dent Assoc. 1974 Nov;50(11):435-8.

[26]. 28)Romanow I. The relationship of moniliasis to the presence of antibiotics in periodontal packs. Periodontics 1964; 2: 298

[27]. (67) Loe., and Silness, J.: Tissue reactions to a new gingivectomy pack. Oral Surg 14: 1305, 1961. 47.

[28]. (81) Greensmith, A. L., and Wade, A. B.: Dressing after reverse bevel flap procedures. J Clin Periodontol 1: 97,1974 